\title{
Drugs Consumer Protection - a Socio- Economic Point of View Regarding Drugs Safety
}

\section{Luiela Magdalena Csorba*}

\section{Summary}

The present paper deals with an actual global issue of the contemporary market: drugs safety. The article is a review paper, built around a hot topic: drugs security and pharmaceutical scandals. The starting points of our analyses are publications and authors from all over the world, with a complex literature relating risky and controversial aspects of drugs consumption. One result of our study is the fact that there are serious breaches of ethics and protocol in clinical trials, not only in those conducted in the Third World countries. In such conditions, where is the real drugs consumer protection?

It is difficult for the global multi-billion dollar drugs market to be totally controlled. That is why, nothing will change within the consumer protection field until the consumers become enough outraged in order to take action and to protect themselves.

Keywords: drugs, consumer protection, selfprotection, scandals, safety.

JEL: M31, D18, 112.

\section{Introduction}

he drugs consumer protection aim is
to ensure the rights of consumers, as well as a fair trade, competition and accurate information in the drugs market. Laws all over the world are designed to prevent businesses that engage in fraud or specified unfair practices from gaining an advantage over the competitors. They may also provide additional protection for the most vulnerable groups of society. The laws in the pharma field are a form of government regulation with the aim to protect the consumers' rights. For example, a government may require businesses to disclose detailed information about the safety of a drug type and its adverse effects on public health. That way, drugs consumer protection is linked to the idea of consumer rights and to the formation of consumer organizations, which help consumers to make better choices in the marketplace.

The Food and Drug Administration (FDA) and the European Medicines Agency (EMA) are the two main international bodies which among other competencies - approve the drugs designated to meet the demand in our global market. So, the potential consumers might conclude that to consume drugs must be safe. Then why do consumer protection organizations all over the world publish alerts about the risky side of drugs consumption?

Before we answer this question, we will review briefly the way in which the drug market

Assoc. prof. PhD., University "Aurel Vlaicu" of Arad, Romania 


\section{Articles}

is oficially regulated in the United States and in the European Union.

In the US, comprehensive consumer protection dealing with physical products was first applied to drugs, foods and food additives. Regarding pharmaceutical drugs, the inadequacies of the common law were glaringly apparent even at the turn of the $20^{\text {th }}$ century. At that time, the only way to identify a company that was selling dangerous drugs was to have a number of people becoming seriously ill or dying as a result of consuming its products. The common law did not allow customers to inspect or require a seller to prove the safety of a new product prior to its commercial sale. When talking about drugs it is impossible to determine the safety of a product just by inspecting it. That is why, the Pure Food and Drugs Act were enacted in 1906 and the Food and Drug Administration was created in 1927 as the US government initiated an activist role in the pursuit of consumer protection. The 1938 legislation was enacted only after around 100 people had perished when a drug sold on the market was found lethal. This was a reason why a large scale animal testing and human clinical trials were conducted by the FDA regulations. The 1938 Act also required the FDA to classify all drugs as either prescription or nonprescription, the latter commonly referred to as over-thecounter drugs. The Drug Efficacy Amendment (1962) required drug manufacturers to prove to the FDA that their products were both safe and effective (fda.gov/cder, 2018).

It used to take pharmaceutical companies several years to prove that their products were safe and effective. Recognizing this problem, the Food and Drug Modernization Act was passed in 1997 and included provisions for speeding up approvals of new drugs, especially those that have a high potential for therapeutic gain and those for which there are no satisfactory alternatives available on the market. Nowadays, FDA regulates over $\$ 1$ trillion worth of products, which account for 25 cents of every dollar spent annually by American consumers, (Jackson et al., 2010).

Across the Atlantic, The European Medicines Agency is an agency in charge of the evaluation of medicinal products, which was known from 1995 to 2004 as the European Agency for the Evaluation of Medicinal Products. Roughly similar to the American Food and Drug Administration, but without FDA-style centralization, EMA was set up in 1995, with funding from the European Union and the pharmaceutical industry, as well as indirect subsidy from the member states, in an attempt to harmonize (but not replace) the work of the existing national medicine regulatory bodies. The hope was that this plan would not only reduce the $€ 350$ million annual cost drug companies incurred by having to win separate approvals from each member state, but also that it would eliminate the protectionist tendencies of the states unwilling to approve new drugs that might compete with those already produced by domestic drug companies. The EU is currently the source of about one-third of the new drugs brought into the world market each year (Sherwood, 2008).

The main responsibility of EMA is the protection and promotion of public and animal health, through the evaluation and supervision of medicines for human and veterinary use. More specifically, it coordinates the evaluation and monitoring of centrally authorized products and national referrals, developing technical guidance and providing scientific advice to sponsors. The Agency decentralizes its scientific assessment of medicines by working through a network of about 4500 experts throughout the EU. To really protect public health before new drugs enter the market, they must be authorized by the European Medicines Agency. 


\section{Articles}

In 2012, the European Union was still examining the legislative proposal regarding the drugs for human use. In March 2014, the EU Regulation no. 282/2014 of the European Parliament and of the Council on the establishment of a third Programme for the Union's action in the field of health (20142020) was adopted. It will support actions related to transmissible diseases and other threats concerning general health, human cells and tissues, blood, human organs, medical devices and drugs. The financial package for the implementation of the Programme for this period is EUR 449,394,000. The annual appropriations shall be authorised by the European Parliament and the Council, within the limits of the multiannual financial framework (eur-lex.europa.eu, 2018).

Creating incentives for the further development of medicines is a relevant measure in the fight against diseases, especially in the developing countries. The EU has been losing ground in pharmaceutical innovation, the investments in research and development being gradually transferred from Europe to US and Asia. Also, the sector is becoming increasingly globalized, which means new opportunities through access to new markets and a global division of labor.

In conclusion we have to underline that it is a part of the FDA's and EMA's activity to see if the medicines and medical devices used by the consumers all over the world are safe and effective.

\section{Pharmaceutical scandals - a literature review}

The term "Big Pharma" describes large pharmaceutical corporations which inject billions of dollars into research, to cure diseases around the world. At the same time, the pharmaceutical industry all over the world spends a lot of money sending sales representatives to the doctors' offices, to
Drugs Consumer Protection - a Socio-Economic Point of

View Regarding Drugs Safety

convince them to use their products. That way, more than $95 \%$ of all doctors had a relationship with the pharmaceutical industry, some of them receiving payments from pharmaceutical companies, often as speakers on behalf of a certain drug. Yet, are nowadays all the promoted drugs safe or licensed?

All over the world, there are a lot of discussions and controversies regarding drugs safety. Not all the drugs cause injuries or death. We cannot deny the fact that the most useful drugs are effective and, for the most part, safe. Let us take as example, Penicillin. Except for people who are allergic to it, penicillin is virtually nontoxic. On the other hand, barbiturates, which were once commonly used as sleep aids, can interfere with breathing, dangerously lower blood pressure, and even cause death if taken in excess. Clozapine is another example. This drug often helps people with schizophrenia when all other drugs have proved ineffective. But Clozapine has a serious side effect: it can decrease the production of white blood cells, which are needed to protect against infection (Duncan and Gold, 1982).

In the last years, global Pharma giants have paid fines to the tune of $\$ 11$ billion for promoting drugs for use beyond any licensed condition. Novartis ended up paying $\$ 420$ million; Pfizer paid $\$ 2.3$ billion in related scandals. The $\$ 3$ billion fine against GlaxoSmithKline in 2012 is the largest fine ever imposed on a pharmaceutical company by the U.S. Department of Justice. GlaxoSmithKline illegally marketed Paxil and Wellbutrin antidepressant drugs. The government said Paxil was unlawfully promoted to treat patients under the age of 18 , while Wellbutrin approved for major depressive disorder was promoted for unapproved uses such as weight reduction and treatment of sexual dysfunction. Although this was the largest pharmaceutical fine in history, it amounted to an insignificant 


\section{Articles}

punishment for GlaxoSmithKline, accounting for only $11 \%$ of the associated revenue. GlaxoSmithKline headed the payout list for the decade, ponying up $\$ 7.628$ billion more than double that of the runner-up Pfizer, at $\$ 3.458$ billion, according to the consumer watchdog group Public Citizen (businessethics.com, 2019).

Big Pharma has written more than $\$ 30$ billion in checks in the last ten years to resolve the government allegations according to statistics compiled by Public Citizen. Thirtyone firms in the last quarter of a century were repeaters, with two or more settlements. Glaxo and Pfizer again led the list, with each entering into 31 settlements with federal or state agencies since 1991, the research showed. Neither firm responded to requests for comment (Feldman, 2016).

Tabel no. 1. Drug company settlements 2006-2015

\begin{tabular}{|l|l|l|}
\hline Company & $\begin{array}{l}\text { Total penalties } \\
\mathbf{2 0 0 6 - 2 0 1 5}\end{array}$ & $\begin{array}{l}\text { Number of } \\
\text { settlements } \\
\mathbf{2 0 0 6 - 2 0 1 5}\end{array}$ \\
\hline GlaxoSmithKline & $\$ 7.628$ billion & 26 \\
\hline Pfizer & $\$ 3.458$ billion & 28 \\
\hline Johnson\&Johnson & $\$ 2.822$ billion & 18 \\
\hline Merck & $\$ 1.890$ billion & 26 \\
\hline Abbott & $\$ 1.822$ billion & 15 \\
\hline Eli Lilly & $\$ 1.706$ billion & 14 \\
\hline Teva & $\$ 1.471$ billion & 13 \\
\hline Novartis & $\$ 1.230$ billion & 18 \\
\hline Amgen & $\$ 901$ billion & 12 \\
\hline AstraZeneca & $\$ 669$ billion & 10 \\
\hline Purdue & $\$ 646$ billion & 5 \\
\hline Allergan & $\$ 601$ billion & 2 \\
\hline Daiichi Sankyo & $\$ 586$ billion & 6 \\
\hline $\begin{array}{l}\text { Bristol-Myers } \\
\text { Squibb }\end{array}$ & $\$ 583$ billion & 10 \\
\hline Mylan & $\$ 566$ billion & 20 \\
\hline Others & $\$ 3.812$ billion & 151 \\
\hline Total & $\$ 30.391$ billion & 374 \\
\hline
\end{tabular}

Source: Public Citizen (business-ethics.com, 2019) Note: The number of settlements includes civil settlements and criminal penalties paid to federal and state agencies
The global health care giant Johnson \& Johnson and its subsidiaries paid in 2013 more than $\$ 2.2$ billion to resolve criminal and civil liability arising from allegations relating to the prescription drugs Risperdal, Invega and Natrecor, including promotion for uses not approved as safe and effective by the FDA and payment of kickbacks to physicians and to the nation's largest long-term care pharmacy provider. The global resolution is one of the largest health care fraud settlements in the U.S. history, including criminal fines, forfeiture totaling \$485 million and civil settlements with the federal government and states totaling $\$ 1.72$ billion. The pharmaceutical industry's representatives argue that they are working hard to enact policies and take actions that will restore the industry's reputation (justice. gov/opa, 2017).

In 2004, Big Pharma Company, Merck, announced a recall of the popular anti-pain medication, Vioxx. The FDA found that Vioxx put patients at a significantly greater risk for heart attack and stroke. Later reviews found that 55,000 deaths might have occurred because of Vioxx. Fines later cost Merck more than $\$ 900$ million. In 2011, the company was involved in a fraudulent activity regarding the components of its MMR (measles, mumps and rubella) vaccine, too (biospectrumasia. com, 2018).

Bristol-Myers Squibb paid $\$ 515$ million in fines after it was discovered that the company marketed its antipsychotic drug, Abilify, to treat conditions the drug was not approved to treat. In addition, Bristol-Myers Squibb sent sales teams to nursing homes to promote the drug, although they knew it had potentially fatal side effects on the elderly. The government also accused the company of paying medical professionals, as well as pharmacists, to dispense the product, by offering those kickbacks and vacations. 


\section{Articles}

European medicines giant Roche had been alleged for working with national medicines agencies to investigate deficiencies in the medicine-safety reporting system of Roche. In May 2012, The Medicines and Healthcare products Regulatory Agency from the UK (MHRA) filed a report about the deficiencies post inspection. The company had identified about 80,000 reports for medicines that were marketed by Roche in USA that had not been evaluated to determine whether or not they should be reported as suspected adverse reactions to the EU authorities. About 15,161 reports of death of patients were included in these reports, but the exact reason for these deaths was not known.

What is known as off-label marketing (promoting drugs for uses other than those approved by the FDA) dominates the list of settlements. While doctors can legally prescribe pills for off-label use, drug companies cannot push medicines for such purposes (Feldman, 2016).

After reaching a peak of $\$ 6.35$ billion in 2012, settlements have fallen. Public Citizen's report cites, as possible reasons, a shift in the focus of prosecutions and free speech court rulings involving drug marketing. In one of those cases, a drug manufacturer won a preliminary injunction after suing the FDA, claiming that restrictions on off-label promotion clashed with its First Amendment rights (business-ethics.com, 2019).

In 2009, ProPublica (a nonprofit investigative journalism organization) launched a "Dollars for Docs" database. The data largely reflected disclosures that drug companies were required to make under settlements stemming from improper marketing allegations. A federal Sunshine Act followed, requiring more companies to publicly disclose payments to doctors (Feldman, 2016).

Starting from this point of view, from publications and authors with a complex
Drugs Consumer Protection - a Socio-Economic Point of View Regarding Drugs Safety

literature relating the controversial aspects of the last nearly 100 years of drug manufacturing and from a Top Ten with the Biggest Medical Scandals in the History which was published on-line in 2013 (topmastersinpublichealth. com, 2015), let's have a short overview on some drugs categories and their related risks (biospectrumasia.com, 2018).

First of all, we take a look at the vaccine market. Most people do not realize that governments are forced to pay out damages to people injured and killed by vaccines, on a regular basis. Between 1989 and July 1, 2014, only in the US, 3,645 compensation awards were made by the National Vaccine Injury Compensation Program (VICP) (amounting to over $\$ 2.7$ billion in awards and $\$ 113.2$ million to cover legal costs) and 9,786 claims have been dismissed (amounting to $\$ 62.8$ million paid to 4,925 dismissed claimants to cover legal costs) (hrsa.gov, 2016).

While judges are deciding to compensate victims of vaccine injuries and death in a court of law from lawsuits brought by the victims' attorneys, they are not technically "criminal" cases, because the laws give total legal immunity to drug companies manufacturing and selling vaccines all over the world. If a consumer is injured or dies as the result of a faulty vaccine, he cannot sue the drug company. The court that hears these cases is a special "vaccine court," and not a regular civil court (desmoinesregister.com, 2018).

Let us analyse some of the biggest stories of the vaccine scandals (healthimpactnews. com, 2016).

The story of how vaccines came to be questioned as a cause of autism dates back to the 1990s. In 1995, a group of British researchers published a cohort study in the Lancet, showing that individuals who had been vaccinated with the measlesmumps-rubella vaccine (MMR) were more likely to have bowel disease than individuals 


\section{Articles}

who had not received MMR (Wakefield et al., 2012). Part of this hypothesis - that vaccination was associated with autism had been suggested previously by a few researchers like Fudenberg (in a small pilot study published in a non-mainstream journal) and Gupta in a review of possible treatments for autism. This hypothesis had not been systematically investigated when Wakefield began to analyse it.

Though in the paper they stated that they could not demonstrate a causal relationship between MMR vaccination and autism, Wakefield suggested in a video released to coincide with the paper's publication that a causal relationship existed between the MMR and autism. He then recommended that the combination MMR vaccine be suspended in favor of single-antigen vaccinations given separately over time (Horton, 2004).

Reaction to the Wakefield publication was immediate. Press outlets covered the news widely and frightened parents began to delay or completely refuse vaccination for their children, both in Britain and the United States, and later all over the world. An inevitable consequence of the report was that MMR vaccination rates fell in the UK and Ireland, resulting in significant increases in cases of and even deaths related to - mumps and measles. MMR vaccination rates in England dropped in response, from more than $90 \%$ to $80 \%$ or lower - well below the level required for building up herd immunity to measles. Unsure of the right decision to make several parents choose not to immunise their children, resulted in a significant increase in the number of cases of measles and mumps: while only 56 cases were confirmed in Wales and England in 1998, 1,348 were confirmed by 2008 (Laurance, 2004).

In 2004, an investigation by "The Sunday Times" journalist Brian Deer finally revealed that Wakefield had manipulated the evidence in his paper and also had various conflicts of interests that were not divulged. Wakefield's paper was finally fully withdrawn in 2010 - the same year in which he was struck off from the General Medical Council (healthimpactnews. com/2014).

Complete details regarding the history of the link between MMR and autism sustained by Wakefield et al., are presented in the paper by Sathyanarayana Rao and Andrade (2011). This scandal impacted the MMR vaccine market until nowadays, when more and more people refuse to accept the vaccine.

At the beginning of September 2014, a Pennsylvanian federal judge ruled in favor of whistleblowers who have accused Merck Company of lying about the efficacy of its MMR. This story did garner mainstream news coverage back in 2012, before Merck's attorneys appealed and tried to get the case thrown out of court. Two former employees accused the drugmaker of overstating the effectiveness of its mumps, measles and rubella vaccine. At the same time, there are a lot of mothers of autistic children who were absolutely convinced that their kids had been injured by vaccines.

The scientists claim: "Merck defrauded the U.S. government by causing it to purchase an estimated four million doses of mislabeled and misbranded MMR vaccine per year for at least a decade, and helped ignite two recent mumps outbreaks that the allegedly ineffective vaccine was intended to prevent; the victims in that process are millions of children who every year are given a mumps vaccine that does not provide them with an adequate level of protection", (forbes.com, 2016).

Over the next years, the possibility of a link between MMR and autism was studied exhaustively. In 2015 the federal officials and industry representatives had discussed a disturbing new study that raised alarming 


\section{Articles}

questions about the safety of a host of common childhood vaccines administered to infants and young children. In the USA more than 500,000 kids suffer from autism, and pediatricians diagnose more than 40,000 new cases every year. The disease was unknown until 1943, when it was identified and diagnosed among eleven children born in the months after thimerosal was first added to baby vaccines in 1931. Some skeptics dispute that the rise in autism is caused by thimerosal-tainted vaccinations. According to a CDC epidemiologist, who had analyzed the agency's massive database containing the medical records of 100,000 children, the mercury-based preservative in the vaccines - thimerosal - appeared to be responsible for a dramatic increase in autism and a host of other neurological disorders among children.

An increasing number of research studies indicate a link between thimerosal and speech delays, attention-deficit disorder, hyperactivity and autism. Since 1991, when the CDC and the FDA recommended that three additional vaccines with added preservative must be given to extremely young infants - in one case, within hours of birth - the estimated number of cases of autism have increased fifteenfold, from one in every 2,500 children, to one in 166 children. They argue that the increase is a result of a better diagnosis - a theory that seems questionable at best, given that most of the new cases of autism are clustered within a single generation of children (Geier et al., 2015).

In the review Clinica Chimica Acta (2015), Geier, King, Hooker, Dorea, Kern and Sykes published a paper which shows the link between thimerosal and a lot of neurological diseases, concluding that this substance is toxic for the human cells: "You couldn't even construct a study that shows thimerosal is safe. It's just too darn toxic. If you inject thimerosal into an animal, its brain will sicken.
Drugs Consumer Protection - a Socio-Economic Point of

View Regarding Drugs Safety

If you apply it to living tissue, the cells die. If you put it in a petri dish, the culture dies. Knowing these things, it would be shocking if one could inject it into an infant without causing damage", says Haley, who heads the chemistry department at the University of Kentucky (globalresearch.ca, 2015).

Autism rates in developing countries have risen remarkably in the past 30 years. For children born in 1992, according to the U.S. CDC, about 1 in 150 would be diagnosed with an autism spectrum disorder (ASD). For children born in 2004, about 1 in 68 children would receive an ASD diagnosis. It is difficult to compare autism rates from the 1990s and later with rates from the 1940s through the 1980s: in earlier years, autism was associated primarily with very severely affected individuals and the rate of autism was estimated to be only about 1 in 10,000 people (Rice et al., 2012).

Researchers and worried parents alike have speculated about causes of autism, and the issue has been widely studied. Concerns about the vaccination reached as far as the United States and Japan. The role of vaccines has been questioned, along with other possible risk factors, such as genetic predisposition, advanced parental age, and other environmental factors. Vaccines have perhaps received more scrutiny than any other speculated cause of ASD, but the great majority of scientists, physicians and public health researchers have come to the conclusion that there is no association between vaccines and autism.

Which is the real evidence against thimerosal? From the very beginning, the scientific case against the mercury additive has been overwhelming. The preservative used in vaccines contains ethylmercury, a potent neurotoxin. Truckloads of studies have shown that mercury tends to accumulate in the brains of primates and other animals after 


\section{Articles}

they are injected with vaccines, and that the developing brains of infants are particularly susceptible to. In 1977, a Russian study found that adults exposed too much lower concentrations of ethylmercury than those given to the American children which still suffered brain damage years later. Russia banned thimerosal from children's vaccines twenty years ago, Denmark, Austria, Japan, Great Britain and all the Scandinavian countries have since followed suit. In contradiction, numerous epidemiological studies performed since the "Wakefield scandal" has also provided additional evidence that there is not a link between thimerosal and autism. Today, thimerosal is no longer used in most childhood vaccines, though some forms of influenza vaccine available in multi-dose vials may contain the preservative.

Most scientific and medical experts are pleased that no connection exists between vaccines and autism or other neurodevelopmental disorders. Still, critics continue to question the issue. Researchers continue to examine these questions, but there is no evidence that these factors play a role in autism development. Most autism researchers hold that the causes of autism are many, but do not involve vaccines (National Institute of Health, 2018).

Another controversed vaccine is HPV (human papillomavirus). The criminal charges against the HPV vaccine were so numerous that it would take a completely separate article to try and cover them all. A hazardous case happened in India. A Supreme Court case involved a fraud during the Gardasil HPV vaccine trials, where several girls died. Vaccine trials were conducted on thousands of girls aged between 9 and 15. Many of the girls fell ill, and at least 7 died, and it was claimed in the lawsuit that in most of these cases, the girls and their parents did not even know what kind of vaccine trial they were participating in (articles.economictimes. indiatimes.com, 2016).

British manufacturer GlaxoSmithKline was fined by the Chinese government for a record Rmb3bn (nearly $\$ 500$ million) for bribing doctors to increase sales. GSK markets three different vaccines in China: HIV, Influenza and Hepatitis $B$ vaccine. Chinese authorities began investigating the company in June 2013, laying bare a tale of intrigue involving a mysterious sex tape, whistleblowers, private investigators and a culture of bribery and graft in China's vast medical industry. The Wall Street Journal reports that five of the company's managers were convicted of bribery-related charges and received suspended prison sentences (wsj. com/articles, 2015).

Governments are settling cases regarding vaccine injuries and deaths, and most of those are for the very risky annual flu shot. For example, in the US, if a consumer is one of the few who are successful in litigating against the U.S. government, the settlement is paid out of a special trust fund called the Vaccine Injury Compensation Trust Fund. This is funded by a tax revenue of around $\$ 0.75$ per vaccine, and not by the pharmaceutical companies.

The U.S. government is also the largest purchaser of vaccines, spending more than $\$ 4$ billion annually to purchase vaccines. The Centers for Disease Control estimated that 732,000 American children were saved from death and 322 million cases of childhood illnesses were prevented between 1994 and 2014 due to vaccination. The measles vaccine has decreased childhood deaths from measles by $74 \%$. Ingredients, such as thimerosal, formaldehyde and aluminum, can be harmful in large doses but they are not used in harmful quantities in vaccines. The FDA requires up to 10 or more years of testing for all vaccines before they are licensed, and then they are monitored by the 


\section{Articles}

CDC and the FDA to make sure the vaccines and the ingredients used in the vaccines are safe (drugwatch.com/ssri, 2016).

The vaccine manufacturing industry does not like losing market share, so they are using their connections with the governments, to take away personal rights and liberties in medical choices. With the help of the mainstream media, they have a willing and compliant public. They would like mandatory vaccine policies in place at the local, state and national levels, because their products cannot survive in a free market. But mandatory vaccination violates the fundamental consumers' right. Each consumer around the world has the right and liberty to make his own choice when choosing to consume a product (healthimpactnews.com, 2014).

Secondly, we will analyse briefly the antidepressants and SSRIs market. Selective serotonin reuptake inhibitors (SSRIs) are antidepressants that work by altering the levels of a mood-enhancing chemical called serotonin. The body naturally produces serotonin and keeps it at a certain level, but SSRIs can increase that level by blocking (inhibiting) the reabsorption (reuptake) of serotonin. SSRIs are considered third-generation antidepressants and are known for having fewer side effects than older antidepressants. SSRIs are prescribed to treat depression, anxiety, panic attacks and personality disorders. They have been shown to be more effective in severe cases of depression than in mild cases. But they are also linked to a great number of side effects, like birth defects, sexual side effects, fatigue, weight loss, apathy, insomnia, headaches, pupil dilation, and also violence and suicidal thoughts and actions, especially by teenagers.

The first drug in the class known as SSRIs broke into the U.S. market in 1988 under the brand name Prozac. In 2002, Prozac was
Drugs Consumer Protection - a Socio-Economic Point of View Regarding Drugs Safety

approved by the FDA for use in children aged 8 and older. As the number of children being treated for depression with Prozac increased, doctors observed an alarming number of reports of suicidal thoughts, and even actions taken to hurt themselves.

Prozac helps many people struggling with clinical depression, but it can also be a risky drug to take. Prozac abuse is common, although experts do not consider the drug to be habit-forming. There is always the possibility of becoming dependent on a drug, and there is also the risk of dangerous side effects (Duncan and Gold, 1982).

Prozac addiction may be uncommon, but abuse of this drug is not. Abusing it means increasing the risk of experiencing side effects. It can also mean that the side effects will be more severe. Possible side effects of Prozac include drowsiness, excessive sweating, dry mouth, sore throat, loss of appetite, weight loss, nervousness, nausea and so on. The rare but more serious side effects include trouble breathing, a rash and hives, joint pain and swelling, confusion, fever, hallucinations and seizures (drugaddictiontreatment.com, 2015).

By 2005, antidepressants like Prozac had become the most prescribed drugs. Today, about a dozen SSRIs are prescribed, including Paxil, Zoloft and Prozac, all over the world (because of the globalization of the drug market).

Paxil was introduced to the U.S. market in 1992 by GlaxoSmithKline to treat depression, but this SSRI also is the first approved by the FDA to treat panic attacks. Paxil, however, is considered more dangerous to a fetus, and women are urged to avoid it during pregnancy.

Zoloft is a popular antidepressant that Pfizer began selling in 1991. This drug shares the higher rate of birth defects that most SSRIs are linked to, such as heart defects and persistent pulmonary hypertension of the newborn. Studies show that mothers taking Zoloft in 


\section{Articles}

the first trimester were 2.8 times more likely to have the abdominal defects of gastroschisis and omphalocele, in which a hernia allows organs to float outside the body of the fetus, Faupel (Horowitz and Weaver, 2013).

A survey entitled "Antidepressants and Suicide Attempts in Children", Cooper et al. (2014) was published in the Pediatrics review. The objectives of the study were to find data showing a possible increased risk for suicidal behavior among children and adolescents treated with selective serotonin reuptake inhibitors (SSRIs) and serotonin-norepinephrine reuptake inhibitors (SNRIs), antidepressants which have created significant concern among patients, families and providers, including concerns about the risk of individual antidepressants.

A retrospective cohort study included 36 842 children aged 6 to 18 years, enrolled in Tennessee Medicaid between 1995 and 2006, who were new users of one of the antidepressant medications. The results showed that 419 cohort members had a medically treated suicide attempt with explicit or inferred attempt to die confirmed through medical record review, including 4 who comitted suicide. The rate of confirmed suicide attempts for the study drugs ranged from 24.0 per 1000 person-years, to 29.1 per 1000 person-years. Users of multiple antidepressants concomitantly had increased risk for suicide attempts.

In this population-based study of children recently initiating an antidepressant therapy, there was no evidence that risk of suicide attempts differed for commonly prescribed SSRI and SNRI antidepressants.

The FDA issued official warnings in 2006 for an increased risk of PPHN (a serious breathing problem in newborns) and Serotonin Syndrome in pregnant patients taking SSRIs. PPHN is the condition that often goes undetected during pregnancy and can lead to a baby being born with serious heart and lung difficulties. Serotonin Syndrome occurs when a patient accumulates too much serotonin in the brain - either from overdosing on an SSRI or taking a combination of medicines that boost the serotonin levels beyond what the brain can handle. With this condition, the onset can occur within minutes and be fatal if not treated immediately.

Because antidepressant medications are such big business for drug manufacturers, the pharmaceutical industry reacts slowly to research that links these prescription medications to dangerous side effects. Among the two most frightening are birth defects and suicide in children and young adults. The young patients are especially vulnerable during the first two months of treatment, when their bodies are adjusting to the medicine. Parents and caregivers should watch for worsening of irritability, nervousness, agitation, mood instability or sleeplessness. Unfortunately, the legal options are limited for family members of someone who committed suicide while taking an SSRI (investopedia.com, 2016).

Another serious concern for SSRI patients is whether they will suffer withdrawal symptoms when they stop taking the antidepressants. SSRIs technically are not considered addictive, because they do not cause cravings in the body when the patient stops taking the drugs. However, doctors do say that these antidepressants make users dependent on them, and they can suffer withdrawal symptoms. Because of this, patients are warned not to stop taking SSRIs suddenly, or they can expect to experience nausea, headaches, dizziness and lethargy.

Many medical and legal professionals believe antidepressant manufacturers need to be held accountable for not fully informing patients about what could happen to them and their babies if they take these prescription medicines. In addition, SSRI victims deserve 


\section{Articles}

to be compensated for mounting medical bills, loss of wages and the pain they have experienced as a result of taking the drugs (investopedia.com, 2016).

Furthermore, let us analyse briefly a few of the drugs related scandals from the past century.

\section{- Jim the Horse Tetanus Scandal, USA} (Early 1900s)

Jim the horse's contribution to saving lives towards the end of the 19th century cannot be questioned. During his time, the onetime milk wagon horse was used to produce over seven gallons of serum that held antibodies used against diphtheria, the contagious and potentially deadly respiratory tract illness, especially dangerous to young children.

Then in early October 1901, Jim was found to have contracted tetanus and was put to sleep. At about the same time, a girl in St. Louis died, and it was discovered that the serum from Jim had caused her death. It was subsequently revealed that serum taken from the horse on September 30 onwards was infected with incubation-phase tetanus.

Unfortunately, the samples had not been tested - a process that could easily have uncovered the infection. Additionally, bottles of serum taken on September 30 had been marked "August 24." Such oversights cost the lives of further 12 children. The episode contributed in part to the passing of the United States Biologics Control Act of 1902 and paved the way for the introduction of the FDA in 1906.

\section{- Elixir Sulfanilamide Mass Poisoning, USA (1937)}

The United States Federal Food, Drug and Cosmetic Act (FDCA) came into effect in 1938. The act gave the FDA the power to oversee the safety of food, drugs and cosmetics. In a way, the FDA was born partially as a result of the 1937 Elixir Sulfanilamide disaster.
Drugs Consumer Protection - a Socio-Economic Point of

View Regarding Drugs Safety

Over 100 people were poisoned and died when sulfanilamide, an antibiotic, was dissolved in diethylene glycol (DEG) and marketed as Elixir Sulfanilamide. Despite reports indicating that DEG was dangerous to humans, such information was not widely known about, and the chief pharmacist at drugs manufacturer S. E. Massengill Company was uninformed. At the time, there were no rules demanding safety testing of new medicines before they went on sale. And while drug companies routinely carried out animal testing, in this case Massengill had not undertaken any.

Soon after the raspberry-flavored elixir hit the market in September 1937, there were reports of deaths and subsequent investigations isolated the cause. The scandal led to the passing of the FDCA, but the Massengill Company was only subject to a minimum fine due to the stipulations of the previous 1906 Pure Food and Drugs Act. Still, with his trial pending, the company's chief pharmacist took his own life.

\section{- Thalidomide Birth Defects}

\section{Scandal, Germany and Worldwide (1950s-1960s)}

The thalidomide distribution scandal of the late 1950s and early 1960s left a lasting effect on the world. Released as a sedative drug in the late 1950s, thalidomide was also found to ease the effects of morning sickness. The drug was sold from 1957, but it was withdrawn in 1962, when it was discovered that it was capable of interfering with developing fetuses and causing birth defects.

Initially, thalidomide was held to be a "wonder drug." The use of medication during pregnancy was not thoroughly regulated. Drugs were not properly tested for the possible danger they posed to babies in the womb. Back then, scientists did not even think that drugs taken by a pregnant woman could harm a growing fetus. Ultimately, thousands 


\section{Articles}

of pregnant women took thalidomide during its five years on the market, and the effects were horrendous. Across 46 countries, over 10,000 children were born with defects like phocomelia. This disorder commonly results in abnormalities to the arms and legs, but it can also have an impact on other parts of the body. In the UK alone, around 2,000 babies were born with birth defects resulting from thalidomide; roughly 1,000 died within a few months, while 466 of those affected were still alive in 2010. The German Grünenthal Group company, which created the drug, issued an apology in 2012, more than 50 years after the drug first went on sale.

\section{- HIV-Tainted Blood Scandal, Japan (1980s)}

The FDA was implicated in a controversial story involving drugs giant Bayer Corporation, brought to light by the New York Times. Factor VIII, a drug for treating mostly hemophiliac children was contaminated with the HIV virus. When American hemophiliacs contracted HIV after using the injected, blood-clotting drug made from unheated blood concentrates, the FDA recommended that Bayer dump their surplus on Japan, Malaysia, Singapore, Indonesia and Argentina. That way the company could still reap profits from sales, despite it being pulled from the US market.

In 1983, Japan's Ministry of Health and Welfare was informed about a U.S licensed heat-treated blood product that could kill HIV. When attempts were made to license this product in Japan, the country's chief provider of blood products, the Japanese Green Cross Corporation, strongly objected, stating that the product would provide unfair competition.

The product was not taken up, and the Japanese Ministry of Health acted by ordering that untreated blood products be screened, by carrying out tests on heat-treating and by encouraging the public to give blood. In the meantime, the Green Cross Corporation distributed safety guarantees regarding their unheated blood products to patients - a significant number of whom were afflicted with hemophilia - and the decision proved disastrous.

During this time period, it was thought that up to 2,000 Japanese hemophiliac patients contracted HIV through tainted blood products. Prominent officials in Japan's Ministry of Health and Welfare, a top hemophilia doctor and company executives were later indicted for involuntary manslaughter. In Hong Kong and Taiwan alone it is estimated that over one hundred hemophiliac patients, including a two-year old child, contracted HIV after using the tainted medicine (i-sis.org.uk, 2016).

\section{- Toxic Cough Syrup, Panama (2007)}

In 2007, 70 years after the infamous Elixir Sulfanilamide poisoning scandal in the US, a similar outbreak caused the tragic loss of hundreds of lives. In Panama, pharmaceutical manufacturers used diethylene glycol, which is commonly used in antifreeze and brake fluid, to make cough syrup, mistakenly believing it to be glycerine. The offending ingredient led to no less than 365 deaths in Panama and was traced back to China.

At first, the investigation was difficult, but it was discovered that the imported diethylene glycol used in the medicine was originally named "TD glycerine," which in China apparently indicates that it is a glycerine substitute. China denied responsibility for the scandal. However, The New York Times later found out that the Chinese manufacturer was not even licensed to make pharmaceutical ingredients.

Moreover, this kind of contamination is not uncommon. In 2009, it was reported that 84 babies, if not more, had died in Nigeria after ingesting cough syrup also believed to have been contaminated with diethylene glycol. In a 1995 article in the British Medical Journal, American pediatrician M. L. Bennish, who had 


\section{Articles}

been a key player in cracking the Panama case, estimated that such poisonings could be responsible for "tens of thousands" of deaths around the world.

\section{- Heparin Adulteration, China (2008)}

In 2008, FDA announced a largescale recall of Heparin after discovering contaminated raw batches of the drug that had been manufactured in China by Scientific Protein Laboratories, a US firm. Heparin is injected into many people to prevent blood clots and is derived from slaughtered animal tissues, such as pigs' intestines and cows' lungs.

The recall followed an alleged 81 deaths and 785 other reports of severe injuries linked to the drug. Investigations identified the contaminant as an over-sulfated derivative of chondroitin sulfate, which can be used as a dietary supplement, but not as a medicine.

The reason for the contamination is thought to have been a combination of cost cutting and a lack of the right breed of pigs in China. By early 2012, the FDA had added 22 Chinese heparin ingredient suppliers to an import alert list. Worryingly, the FDA also stated that it did not have enough money and that it was not up to them to inspect such overseas manufacturers on a regular basis.

\section{- New England Compounding Center Meningitis Outbreak, USA (2012)}

In October 2012, the US Centers for Disease Control and Prevention followed the trail of an outbreak of fungal meningitis back to the contamination of medication administered as epidural steroid injections. Packaged and sold by Massachusetts-based pharmacy, the New England Compounding Center (NECC), the spoiled drugs had been sent to 75 clinics, hospitals and surgeries across 23 states. Between May and September of that year, approximately 14,000 patients received the medication.
Drugs Consumer Protection - a Socio-Economic Point of View Regarding Drugs Safety

By mid-January 2013, 678 people had contracted the fungal disease and 44 had died. Preliminary investigations found dirty, unhygienic conditions at the NECC (including steroid solutions contaminated with fungus). Authorities discovered that the NECC had distributed orders of the drug despite the fact that they were still waiting for test results that would indicate whether or not the shipment was sterile. By December 15, 2012, over 400 litigation proceedings had been launched against NECC.

For this drugs scandals we must add some aspects regarding the drugs test on children, most of them coming from the less developed countries. For example, in 2006, two children suffered serious allergic reactions after being used as "guinea pigs" by the California-based company Ventria Bioscience in Lima, Peru. The children were part of a clinical trial of a genetically modified (GM) rice serum containing two synthetic human proteins, lactoferrin and lysozyme (normally found in human milk and other bodily fluids), not approved for testing in the US or anywhere else in the world. The company was hoping to sell the GM rice as a product capable of providing extra nutrition. Nevertheless, it was unlikely to gain approval for a clinical trial in the US; so, like other companies, it decided to target Third World countries where regulations were lax (i-sis.org.uk, 2015).

The trials in Lima were carried out at the Institute for Child Health and at the Nutrition Research Institute. Ventria had experimented on 140 children between the age of 5 months and 3 years suffering from diarrhea. It is doubtful whether informed consent was obtained. One child became so ill that according to his mother, he was allergic to many foods such as fruit and chocolate. Some specialist in genetics fears that the tests could have untoward long-term consequences. They believe that children 


\section{Articles}

given the GM rice serum could suffer degenerative diseases like Alzheimer's because of damage incurred by the altered proteins. These are just some reasons why Ventria's trial should never have been allowed, anywhere in the world, least of all, on vulnerable infants suffering from diarrhea: it causes debilitating lung inflammation and food sensitivities.

In 1996, the Washington Post revealed that drug giant Pfizer Pharmaceuticals was accused of conducting unethical clinical trials on children in Nigeria. This accusation was made in a Nigerian government report instigated by a whistleblower. An experimental antibiotic, Trovan, was given to the children in a field hospital in Kano where they were treated for a meningitis epidemic. The parents were not told of the drug's unapproved status and they only gave verbal consent to the nurses for its use on the understanding that it would help their children. The report, which lay buried for five years, revealed that five children died after being given Trovan. The pharmaceutical company later concocted and backdated a letter of approval from a Nigerian Ethics Committee (pharmamanufacturing. com, 2016).

According to the Nigerian government report, Pfizer had violated Nigerian Law, the International Declaration of Helsinki and the UN Convention of the Rights of the Child. The discovery of the report has breathed new life into a court action against the company initiated by 30 Nigerian families involved in the trials.

FDA subsequently never approved Trovan for use in treating American children. The FDA non-approval was a blow to Pfizer, which was looking to gain billions of dollars per year from sales. The drug was cleared for adult use in the US, but its use became severely restricted after reports of liver damage and deaths. Trovan is now banned in Europe (i-sis. org.uk, 2015).

Starting from the above analysed drug related scandals and alerts from all over the world we have to underline the fact that there are serious breaches of ethics and protocol in clinical trials, not only in those conducted in the Third World countries. It is not surprising that only in year 2008 alone the FDA received more than 100,000 reports of serious injuries related to adverse drug events, an increase of about $25 \%$ over the previous year, according to the Institute for Safe Medication Practices. Each year more than 770,000 people are harmed or die from adverse drug events. About 30,000 cases of adverse reactions to vaccines have been reported annually to the Vaccine Adverse Event Reporting System since 1990, with 10$15 \%$ classified as serious, being associated with permanent disability, hospitalization, life-threatening illness or death.

In July 2018, Sonawane et al. published an article regarding the serious Adverse Drug Events (ADEs) reported to the FDA in the 2006-2014 period. According to a previous study, from 1998 to 2005, there was a 2.6-fold increase in the reports of serious ADEs. From 2006 to 2014, the number of serious ADEs reported to the FDA increased twofold. A total of 902,323 serious outcomes were reported over the 9-year study period: 244,408 deaths, 72,141 disabilities, and 585,774 other serious outcomes. The relative percentage of reports of deaths was highest during 2012 (32.4\%). The percentage of reports of disability was highest during 2006 (12.1\%) (Sonawane et al., 2018).

The ethical obligations to protect the best interests of children (and adults) in clinical procedures are defined by The Nuremberg Code. The Code was developed in the aftermath of atrocious human experiments during World War II and provides guidance 


\section{Articles}

for protecting human experimental subjects from injury, disability or death. At the same time, a revised voluntary code put in place in 2009 by the Pharmaceutical Research and Manufacturers of America (PhRMA) no longer permits mugs, pens, tablets or other noneducational "reminder" gifts to be dispensed by pharmaceutical companies. When the code was announced, 32 of the 34 member companies of the trade organization signed. Critics argue that lawsuits like these do not stop companies from the unlawful or unethical practices.

There is a need for global regulation in clinical research, so that drugs and trials not approved in one country may not be tested or used in another (i-sis.org.uk/FDAinDrugTrial, 2015).

\section{Consumers' self-protection and responsibility in drugs use}

It is hard to guarantee the protection of the drugs consumers all over the world in the above mentioned conditions, when each country or organization has its subjective opinion regarding this issue. How safe or risky is to consume drugs or vaccines is a controversial hot topic, the opinion being divided into two categories: people who are in favour or people who are against consuming some drugs categories. But, even if somebody chooses to consume or not a drug, this field still remains an open one, having a lot of unsolved problems. The main problems raised against the drugs policy all over the world are, as follows:

1. Counterfeit drugs sold through the Internet and the illegal circulation of some drugs.

2. Drugs sold without medical prescriptions.

3. Drugs with health and social consequences (some drugs are associated with high rates of addiction,
Drugs Consumer Protection - a Socio-Economic Point of

View Regarding Drugs Safety

and, also, drug use may affect the work performance).

4. Experimental tests conducted in the developing countries on vulnerable children.

5. Mandatory vaccination in some countries.

6. Drugs advertising.

The advertising of pharmaceutical products is highly regulated around the world. The most popular way to advertise drugs all over the world are the direct-to-consumer advertising (DTC). But direct-to-consumer advertising is used to drive choice rather than inform the consumer. Because of that, consumers go to their doctors and the pressure to prescribe the advertised drugs begins (who.int/bulletin, 2018).

The US is one of the countries that allow big pharma to advertise prescription drugs directly to consumers. The recent controversies in the USA have led to the development of the PhRMA Guidelines for Pharmaceutical Advertising, which are set to further rationalise DTC advertising approaches worldwide. While the marketing of overthe-counter, non-prescription medication is relatively widespread, only two countries allow prescription drugs to be promoted directly to consumers: New Zealand and the US.

In Europe, there are strict regulatory restrictions in that field. For example, while advertising non-prescription medicines to the public is permitted in the UK, DTC advertising of prescription-only medicines is strictly prohibited. In Europe's largest drug market, Germany, the rules against DTC advertising of prescription pharma products are as stringent as those in other EU countries. In Germany, the Heilmittelwerbegesetz or HWG (The Law on Advertising in the Field of Healthcare) governs pharma advertising. The regulations ban the promotion of product brands where the disease has only one treatment option 


\section{Articles}

available in the market. It has also become mandatory for advertisements to advise the public to consult a doctor or pharmacist. Expert opinions, product recommendations, healthcare professional advice and certain graphic representations are not permitted. In other countries, regulations also allow the advertising of non-prescription medicines, with certain limitations. For example, in France, DTC advertising of non-prescription medicines is permissible only if purchasers are not reimbursed by the social security system. Moreover, disease awareness campaigns are considered legal only if such campaigns do not refer directly or indirectly to the product or therapeutic class. In Spain, DTC advertising is allowed only for medicines that treat minor symptoms (pharmafield. co.uk/features, 2017).

Nowadays, while in the Republic of Moldova individuals and legal entities that have no licence for pharmaceutical activity are not allowed to advertise drugs, in Romania, the Association for Consumer Protection requires from the Ministry of Health to ban the advertising for medicines and the outdoor advertising that encourages self-medication.

More than half of all the prescription drugs cause adverse effects that are not detected until after the FDA or EMA (or other similar organizations) approves them, sometimes many years later. Such delayed detection contributes to the high number of drug-related injuries, all over the world. Some of the delay is inevitable. It is simply not possible to detect every risk before doctors start prescribing a drug. Doing so would require clinical trials that would be prohibitively large, long and costly.

Pharmaceutical companies typically start advertising a drug within a year of approval, long before anyone knows whether its benefits outweigh its risks. The companies may minimize the known risks, often by running distracting or reassuring images while mentioning adverse effects. In the real world, patients may receive lax care that exposes them to greater risks; moreover, doctors are allowed to prescribe approved drugs for unapproved purposes, sometimes for patients at considerably higher risk than the trial volunteers. In such conditions, where is the real drugs consumer protection?

So, we may conclude that one of the main factors why pharma scandals exist is the limitations of the clinical trials submitted to the FDA/EMA before approval. The flaws in the preapproval process cannot assess safety adequately because they are (www.i-sis.org. uk/FDA, 2017):

- too small (involving only about 500 to 3000 volunteers);

- too short (trials may last for just a few months, but some adverse effects develop only after patients take a drug for many years);

- too unrealistic (most trials are conducted under scrupulously controlled conditions, with carefully selected patients in order to demonstrate that the drug works).

Trials often use clinical lab results to determine how well a drug works rather than measuring how often it helps a person avoid having a heart attack. Such measures may present a misleading picture of a drug's risks and benefits.

In addition, the governmental institutions (like FDA for example) may approve some new drugs more quickly than others. The time devoted to preapproval review, particularly for drugs deemed "priority" has dropped substantially since 1992. Congress passed a law designed to speed up the FDA approval process for some drugs to get them to the market faster. But doing so may have come at a significant cost. A 2003 survey of FDA reviewers indicated that they generally felt rushed, and in some cases pressured by their supervisors, in order to approve medications. 


\section{Articles}

A faster review implies a greater chance of hazards emerging after a drug's approval. That way, the FDA has lacked the resources and authority to regulate drug ads effectively. Months can go by before it catches up with misrepresentations, exaggerated claims or inaccuracies. While the 2007 law authorized more FDA staffing to scrutinize ads and more power to regulate them, companies still do not need the agency's go-ahead before running their promotions in most cases, though some do so voluntarily.

Even if all the risks cannot be reliably detected before approval, some are discovered afterwards. Unfortunately, the system for detecting risks after approval is a weak link in the drug-safety system, because of several reasons (merckmanuals.com, 2018):

- Incidents are not reported. Just a small fraction of drug related incidents or adverse drug effects are reported by patients, physicians and other health professionals.

- Studies after approval are not done. Clinical trials published after a drug's approval can reveal previously unknown risks, but companies have usually delayed or avoided them.

- Studies are not published. Drug companies sponsor many studies that are never published in medical journals.

- Surveillance is not adequate. Drug risks can be detected by searching large databases of patient records or insurance claims.

- International institutions like FDA and EMA are not effective. For example, The Institute of Medicine, a private group that advises the government, issued a report in 2007 that sharply criticized FDA's drug-safety efforts.

Because of the above presented issues, a real and effective consumer protection policy in that field is hard to achieve.
Drugs Consumer Protection - a Socio-Economic Point of

View Regarding Drugs Safety

This is the reason why we conclude that the best form of drugs consumer protection is self-protection. That requires two aspects: an informed and a responsible consumer. To use controlled and other drugs responsibly, the consumer must adhere to a list of principles. To these measures we have to add that a well informed and educated drug consumer is a responsible patient, which is of similar importance. That means first of all the fact that, when the consumer starts to take prescription drugs, especially new ones, he has to be prudent. To help ensure that their treatment plan is as safe and effective as possible, consumers should keep their health care practitioners well informed about their medical history, drugs (including overthe-counter drugs and vaccines) and dietary supplements (including medicinal herbs) that they are currently taking, and any other relevant health information (merckmanuals. com, 2018).

At the same time, for an effective selfprotection, each consumer has to take the followings steps (consumerreports.org, 2018):

- to not stop abruptly the consumption of a drug, even if they have heard that the medicine has certain newly discovered risks. Consumers must ask the doctor whether the benefits outweigh the risks and whether other options can achieve adequate results;

- to consider other options. If the consumer does not trust a new drug, he may ask his doctor whether there is an older one on the market, equally effective, but less risky;

- to resist advertising. Consumers should not buy drugs without the doctor's approval, just because they are influenced by advertising;

- to be informed regarding the alerts reports about newly discovered drug risks;

- to report any serious drug reactions to 


\section{Articles}

the doctor, to be further reported to the authorities in that field.

In addition, consumers should not hesitate to ask a doctor, nurse, or pharmacist to explain the goals of treatment, the types of side effects and other problems that may develop, and the extent to which they can participate in the treatment plan

\section{Conclusions}

Drugs consumer protection policies aim not only to sustain and protect the consumers' health and safety by using the legal ways offered by each government, but also to educate and completely inform the population all over the world regarding the dangerous aspect of consuming some drugs categories.

Scientists and organizations across the world spent a lot of time and money on research having the final aim to find out how safe or risky is to consume some drugs, even if the primary goal of pharmaceutical companies is to sell the drugs and to make a profit.

When talking about the vaccines safety, consumers and researchers can be divided into two categories: $P R O$ and $A N T I$ vaccination.

PRO vaccination is the American Academy of Pediatrics who states that: "most childhood vaccines are 90\%-99\% effective in preventing disease". A lot of people agree that vaccines can save children's lives, because the ingredients in vaccines are safe in the amounts used. At the same time, this category of consumers is convinced that the use of vaccines can assure a high immunity of the organism. Of the opposite opinion are people who do not trust vaccination, because it can be risky, causing negative side effects. At the same time, vaccines may contain harmful ingredients or ingredients considered by some people as immoral or objectionable.

The overwhelming majority of parents believe in immunisation for their children, but there are a few parents who do not believe immunisation is right for their own child. Every parent should have access to a qualified health professional to talk about their concerns, the risks of catching the diseases and the benefits and potential risks of immunisation for their own child, and the population in general.

The government should not intervene in personal medical choices. Medical decisions for children should be left to the parents or caregivers. If parents across the world did not vaccinate their children because they fear to expose them to unknown risks, governments must have the ethical responsibility to ensure the individual freedom of the people. No citizens can be forced against their will to be injected with biological products of known or unknown toxicity. Freedom over one's physical person is the most basic freedom of all, and people in a free society should be sovereign over their own bodies. That is why we consider mandatory vaccination as being nonethical, violating the consumers' rights.

A similar safety issue is the risk that some people might be allergic to certain drugs or may be harmed after consuming a drug category with unknown side effects. However, these allergic reactions are not tested or monitored by doctors before the use of these drugs by patients. Therefore, it is of utmost importance to provide consumers with relevant information and individual protection. Even if during the time some aspects regarding drugs risks and their impact on the consumers' health were solved, this field continues to remain an open one, which always will give birth to new controversies, discussions and misinterpretations.

\section{References}

Almashat, S., Preston, C., Waterman, T., Wolfe, S., 2010. Rapidly Increasing Criminal and Civil Monetary Penalties against the 


\section{Articles}

Pharmaceutical Industry: 1991 - 2010, Public Citizen's Health Research Group

Cooper, W. O., Callahan, S. T., Shintani, A., Fuchs, D. C., Shelton, R. C., Dudley, J. A., Graves, A. J., Ray, W. A., 2014. Antidepressants and Suicide Attempts in Children, Pediatrics, vol. 133, no. 2, pp. 1-7.

Duncan, D. F., Gold, R. S., 1982. Drugs and the whole person. Wiley, New York. Chapter 18: Responsibilities of the recreational drug user.

Faupel, C. E., Horowitz, A. M., Weaver, G. S., 2013. The Sociology of American Drug Use. McGraw Hill.

Feldman, P., 2016. Drug companies pay up in illegal marketing cases, but are penalties enough? Business ethics, regulation and legislation, available at https://business-ethics. com/2016/05/05/1606-drug-companies-ponyup-in-illegal-marketing-cases-but-criticswonder-if-penalties-are-enough-see-more-athttp/ [Accessed 25 November 2019].

Fudenberg, H. H., 1996. Dialysable lymphocyte extract (DLyE) in infantile onset autism: a pilot study. Biotherapy, 9(1-3): pp. 143-147.

Geier, D. A., King, P. G., Hooker, B. S., Dórea, J. G., Kern, J. K., Sykes, L. K., Geier, M. R., 2015. Thimerosal: Clinical, Epidemiologic and Biochemical Studies, Clinica Chimica Acta 02/2015, pp. 208.

Geier, D. A., Kern, J. K., King, P. G., Sykes, L. K., Geier, M. R., 2015. A Case-Control Study Evaluating the Relationship Between Thimerosal-Containing Haemophilus influenzae Type b Vaccine Administration and the Risk for a Pervasive Developmental Disorder Diagnosis in the United States, Biological Trace Element Research no. 02/2015; 163(1-2): pp. 28-38.

Gupta, S., 1996. Immunology and immunologic treatment of autism. Proc Natl Autism Assn Chicago, pp. 455-460.
Drugs Consumer Protection - a Socio-Economic Point of View Regarding Drugs Safety

Horton, R. A., 2004. Statement by the editors of The Lancet. The Lancet. 363(9411): pp. 820-821.

Jackson, J., Lyons, T. S., Roberts, J.L., Geary, C, Williams, J., 2010. Use of nutritional supplementation among university recreation users, Recreational Sports Journal, 34(1): pp. 2-8.

Lines, R. The Politics of Drug Use Marginalization (PDF). PASAN, Ontario. Retrieved 14 July 2009.

Laurance, J., 2004. How was the MMR scare sustained for so long when the evidence showed that it was unfounded? The Independent, September [Accessed 30 January 2018].

Nicholson, T., Duncan, D., Oduniyi, O., 2002. Is recreational drug use normal? Journal of Substance Use, 7, pp. 116-123. Available online at http://www.duncan-associates.com/ Is-Recreational-Drug-Use-Normal.pdf.

Rice, C. E., Rosanoff, M., Dawson, G., Durkin, M., Croen, L.A., Singer, A., Yeargin-Allsopp, M., 2012. Evaluating changes in the prevalence of the autism spectrum disorders (ASDs). Public Health Reviews, 34(2): 1.

Robinson, M. B, Scherlen, R. G., 2007. Lies, Damned Lies and Drug War Statistics: A Critical Analysis of Claims Made by the Office of National Drug Control Policy. State University of New York, pp. 97. Retrieved July 29, 2011.

Sathyanarayana Rao, T. S., Andrade, C., 2011. The MMR vaccine and autism: Sensation, refutation, retraction and fraud. Indian Journal of Psychiatry. Apr-Jun; 53(2): pp. 95-96.

Sherwood, T., 2008. Generic Drugs: Overview of ANDA Review Process (PDF). CDER Forum for International Drug Regulatory Authorities. Food and Drug Administration, Office of Pharmaceutical Science. Retrieved 30 January 2010. 


\section{Articles}

Sonawane, K, B., Cheng, N., Hansen, R. A., 2018. Serious Adverse Drug Events Reported to the FDA: Analysis of the FDA Adverse Event Reporting System 2006-2014 Database. Journal of Managed Care \& Specialty Pharmacy, 24 (7), pp. 682-690.

Thomas, K., Schmidt, M. S., 2012. Glaxo Agrees to Pay \$3 Billion in Fraud Settlement. The New York Times. Retrieved July 3, 2012.

Wakefield, A. et al. Retracted, 1998. Ileallymphoid-nodular hyperplasia, non-specific colitis and pervasive developmental disorder in children. Lancet. 351(9103): pp. 637-641.

Weeks, M. R., Dickson-Gomez, J., Mosack, K. E., Convey, M., Martinez, M., Clair, S., 2006. The Risk Avoidance Partnership: Training Active Drug Users as Peer Health Advocates. Journal of Drugs Issues 36 (3): pp. 541-570.

Wilson, R., Kolander, C., 2010. Drug Abuse Prevention: A School and Community Partnership. Jones \& Bartlett Publishers. pp. 147, Retrieved July 29, 2011.

U.S. Dept. of Health and Human Services, National Vaccine Injury Compensation Program, available at http://www.hrsa.gov/ vaccinecompensation/index.html [Accessed 18 January 2016].

CDC. Autism spectrum disorder (ASD). Research [Accessed 29 January 2019].

National Institutes of Health. National Institute of Neurological Disorders and Stroke. Autism spectrum disorder fact sheet [Accessed 30 January 2019].

Text of the Food and Drug Modernization Act, 2018. [Online]. Available: http://www.fda.gov/ cder/guidance/105-115.htm [Accessed 29 July 2018].

http://eur-lex.europa.eu/legal-content/EN/ TXT/?uri=uriserv:OJ.L [Accessed 21 May 2018]. http://www.topmastersinpublichealth.com/10biggest-medical-scandals-in-history/ [Accessed 15 July 2015].

http://www.modernhealthcare.com [Accessed 15 January 2019].

http://ww w.biospectrumasia.com/ biospectrum/analysis/192973/worlds-bigpharma-frauds [Accessed 6 June 2018].

http://www.justice.gov/opa/pr/johnsonjohnson-pay-more-22-billion-resolve-criminaland-civil-investigations [Accessed 28 January 2017].

http://healthimpactnews.com/2014/vaccinescandals-and-criminal-cases-increasein-2014/ [Accessed 8 December 2017].

http://www.pharmamanufacturing.com/ articles/2015/top-stirs-and-scandals-of-2014/ [Accessed 28 December 2016].

http://healthimpactnews.com/2014/state-farmdumped-rob-schneider-for-vaccine-viewsnow-im-dumping-state-farm/ [Accessed 21 June 2016].

http://www.i-sis.org.uk/isisnews/sis30.php [Accessed 28 December 2016].

http://www.i-sis.org.uk/NSADTMB.php [Accessed 28 August 2015].

http://www.i-sis.org.uk/FDAinDrugTrial.php [Accessed 27 August 2015].

http://www.desmoinesregister.com/story/ news/crime-and-courts/2014/09/12/dongpyou-han-seeks-trial-delay-in-isu-aidsvaccine-fraud-case/15537723/ [Accessed 18 March 2018].

http://www.forbes.com/fdc/welcome_mjx. shtml [Accessed 17 May 2016].

http://www.investopedia.com/financialedge/1212/the-true-cost-of-pharmaceuticalscandals.aspx\#ixzz3ZMMkV6bP [Accessed 3 December 2016]. 


\section{Articles}

http://www.globalresearch.ca/vaccinationsdeadly-immunity/14510 December 2015]. [Accessed 15 http://articles.economictimes.indiatimes. com/2014-08-31/news/53413161_1_hpvvaccine-cervarix-human-papilloma-virus/2 [Accessed 5 December 2016].

http://www.wsj.com/articles/glaxosmithklinefound-guilty-of-bribery-in-china-1411114817 [Accessed 27 October 2015].

http://www.drugwatch.com/ssri/fda-warnings/ [Accessed 19 December 2016].

http://healthimpactnews.com/2014/10-moreyoung-women-file-criminal-complaints-dueto-injuries-from-gardasil-vaccine-in-france/ [Accessed 8 August 2015].

http://www.drugaddictiontreatment.com/ types-of-addiction/prescription-drug-
Drugs Consumer Protection - a Socio-Economic Point of View Regarding Drugs Safety

addiction/how-prozac-can-be-harmful/ [Accessed 19 October 2016].

http://www.i-sis.org.uk/FDACorporateLinks. php [Accessed 11 October 2015].

http://www.merckmanuals.com/home/drugs/ overview-of-drugs/drug-effectiveness-andsafety [Accessed 16 May 2018].

http://www.consumerreports.org/cro/2012/05/ are-prescription-drugs-safe-not-necessarily/ index.htm [Accessed 6 November 2018].

h t t p: / / w w w. who.int / b u lle t in / volumes/87/8/09-040809/en/ [Accessed 10 June 2018].

h t t p: // w w w.pharmafield.co.uk / features/2005/12/Pharmaceutical-direct-toconsumer-advertising-in-Europe [Accessed 12 September 2017]. 